\title{
Bed properties and hydrological conditions underneath McCall Glacier, Alaska, USA
}

\author{
Frank PATTYN, ${ }^{1}$ Charlotte DELCOURT, ${ }^{1}$ Denis SAMYN, ${ }^{1}$ Bert DE SMEDT, ${ }^{2}$ \\ Matt NOLAN ${ }^{3}$ \\ ${ }^{1}$ Laboratoire de Glaciologie, Département des Sciences de la Terre et de l'Environnement, CP 160/03, Université Libre de \\ Bruxelles, Avenue F.D. Roosevelt 50, B-1050 Brussels, Belgium \\ E-mail: fpattyn@ulb.ac.be \\ ${ }^{2}$ Vakgroep Geografie, Vrije Universiteit Brussel, Pleinlaan 2, B-1050 Brussels, Belgium \\ ${ }^{3}$ Institute of Northern Engineering, 455 Duckering Bldg, University of Alaska Fairbanks, Fairbanks, AK 99775-5860, USA
}

\begin{abstract}
During three summer field seasons (2003, 2005 and 2006) we carried out radio-echo sounding measurements with a $5 \mathrm{MHz}$ (central frequency) ice-penetrating radar on McCall Glacier, Arctic Alaska, USA, along the central flowline and 17 cross-profiles. Two-way travel time was, after migration, converted to ice thickness, which, in combination with a recent digital elevation model of the surface of the glaciated area, resulted in a detailed map of the bed topography. This reveals a complex basal topography in the confluence area of the different glacial cirques. The pattern of subglacial water flow following the hydraulic potential gradient was calculated for the whole glacier area and shows a confluence of subglacial water downstream from the confluence of the glacier cirques. From the icethickness map the total ice volume was estimated as slightly less than $0.5 \mathbf{~ k m}^{3}$. Bed reflection power (BRP) was determined for the glacier after correction for ice-thickness dependence. Results reveal a clear relationship between the BRP pattern and basal sliding anomalies along the central flowline.
\end{abstract}

\section{INTRODUCTION}

McCall Glacier is situated at $69^{\circ} 18^{\prime} \mathrm{N}, 143^{\circ} 48^{\prime} \mathrm{W}$, in the northeastern part of the Brooks Range, Alaska, USA. The glacier is $\sim 7.6 \mathrm{~km}$ long and covers an area of $6 \mathrm{~km}^{2}$ (Fig. 1). It extends from an altitude of $2500 \mathrm{~m}$ down to $1365 \mathrm{~m}$ at the terminus, with an equilibrium-line altitude (ELA) between 2000 and $2400 \mathrm{~m}$ (Nolan and others, 2005). McCall Glacier is known to be a polythermal glacier, with a temperate basal layer along a section of the lower glacier (Rabus and Echelmeyer, 1997; Pattyn and others, 2005). The glacier has been studied extensively, from the International Geophysical Year (1957/58) onwards through to the International Hydrological Decade (1969-72) and from the mid-1990s to the present. These studies have shown that McCall Glacier has been losing mass for decades, and that the rate of mass loss has increased over the past 10-20 years (Rabus and others, 1995; Nolan and others, 2005). Flowline model estimates have shown that accelerated glacier retreat since the early 1990s is related to the recent increase in ELA and the sudden reduction in accumulation-area ratio (AAR) (Delcourt and others, 2008).

To further investigate the basal hydrological controls on the dynamical behavior of McCall Glacier, we reconstructed the basal topography of the glacier, based on an extensive radio-echo sounding (RES)field survey, carried out during the summer seasons of 2003, 2005 and 2006. From the basal topography, the pattern of basal water flow is investigated. Finally, an analysis of bed reflection power (BRP) from the radar signals is presented in relation to ice dynamics.

\section{RADIO-ECHO SOUNDING (RES)}

RES measurements were carried out with a $5 \mathrm{MHz}$ (central frequency) ice-penetrating radar (Narod and Clarke, 1994). The system consists of a monopulse transmitter generating
$1600 \mathrm{~V}$ pulses across a resistively loaded $10 \mathrm{~m}$ dipole antenna, and an airwave-triggered oscilloscope receiver connected to a palmtop computer for digital data recording. Pulses are generated at $512 \mathrm{~Hz}$ and have a bandwidth of $1-200 \mathrm{MHz}$. The system has already been used successfully on several glaciers in Arctic and sub-Arctic regions (Pattyn and others, 2003, 2005). Two longitudinal and seventeen cross profiles were surveyed in August 2003, 2005 and 2006 (Fig. 1). The horizontal distance between successive measurements along each track varied between 19 and $38 \mathrm{~m}$. The network of profiles was concentrated in the confluence area of the branches coming from the upper (UC), middle (MC) and lower (LC) cirques.

On all measurements, static corrections were performed for the trigger delay caused by the $38 \mathrm{~m}$ separation between transmitter and receiver. A propagation velocity of $168 \mathrm{~m} \mathrm{\mu s}^{-1}$ for glacier ice was used, a value obtained from a common-midpoint experiment in the confluence area. Migration was carried out by considering, for a given bedrock echo, the locus of possible reflectors as a semi-ellipse, with transmitter and receiver points at the focal points (Rabus and Echelmeyer, 1997). The bed along a given profile is then the envelope of these intersecting ellipses, as shown in Figure 2 for one of the cross-profiles in the confluence area. The quality of the ice-thickness measurements is estimated from the intersection points of the different radar profiles, leading to root-mean-square errors of 8.38 and $12.04 \mathrm{~m}$ for migrated and non-migrated ice thickness, respectively $(n=22)$.

The two-dimensional basal topography was obtained after interpolation based on a Delaunay triangulation of the measured bedrock profiles combined with a digital elevation model (DEM) of the surrounding area (Fig. 3a), which also resulted in an ice-thickness map (Fig. 3b). The total ice volume of McCall Glacier is estimated as $0.5 \mathrm{~km}^{3}$, with a mean ice thickness $\bar{H}=82.39 \mathrm{~m}$ for a surface of $6.02 \mathrm{~km}^{2}$. 


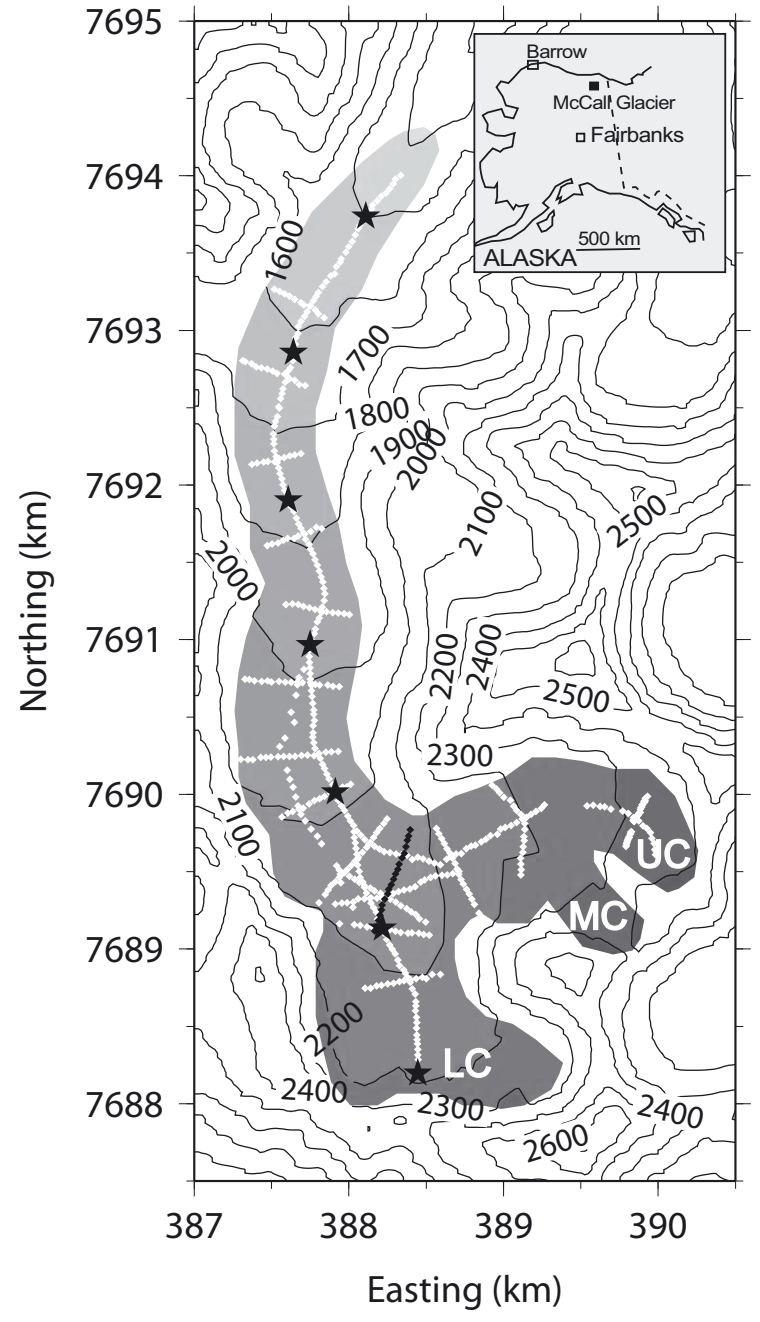

Fig. 1. Surface topographic map of McCall Glacier (UTM). The positions of the radar profiles are shown in white and the profile in Figure 2 is shown in black. Black stars are plotted every kilometer along the flowline. LC, MC and UC indicate lower cirque, middle cirque and upper cirque, respectively.

These values were obtained by simple arithmetic on the icethickness map, excluding the steepest slopes of the accumulation area where ice is generally thin (bergschrund).

From the basal topography and the ice-thickness distributions, a clear distinction can be made between the two major parts of the glacial system: the deeper trench starting from the LC and the shallower tributary coming from the UC and MC. Both systems are delineated by a sudden drop in elevation (Fig. 3a and b). Such thresholds occur at several other places in the glacier and correspond to a prolongation of spurs across the glacier, revealing differential erosion. As such, the McCall Glacier system is composed of a chain of subglacial overdeepenings. The clearest example is given by the overdeepening of the LC and the northern threshold separating LC from the rest of the glacier system. The confluence area clearly shows the existence of a hanging glacier valley coming from $\mathrm{UC} / \mathrm{MC}$ before entering the main trunk originating from the LC (Fig. 2). Except for the overdeepening in the LC, this complex basal topography was not revealed in a previous compilation of the subglacial relief (Rabus and Echelmeyer, 1997), because of their coarser sampling interval.

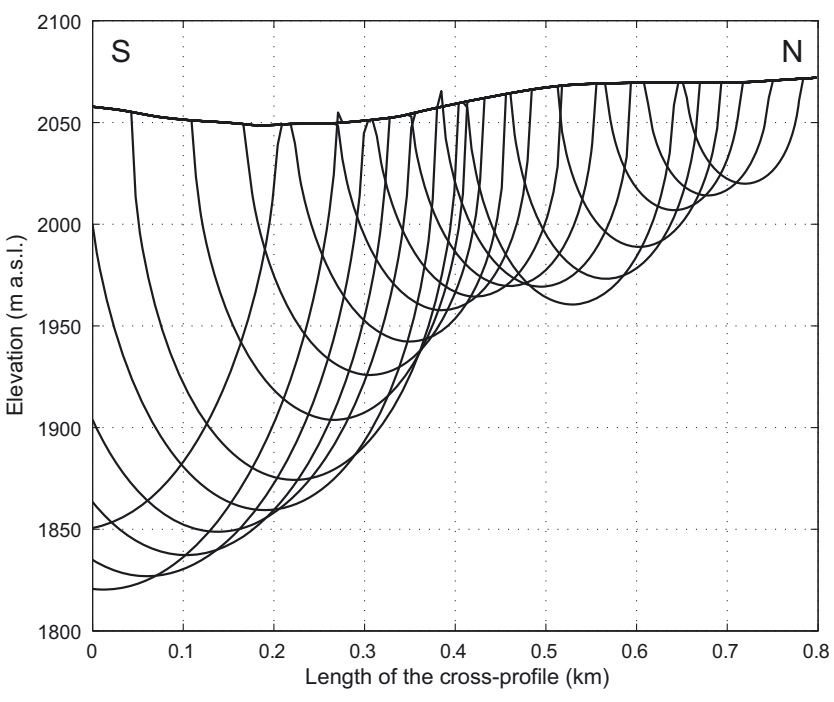

Fig. 2. Construction of ellipses on a cross-sectional profile in the confluence area to account for migration. The migrated bed is then the envelope of the intersecting ellipses. The position of the crossprofile is shown in Figure 1.

\section{SUBGLACIAL HYDROLOGY}

Subglacial water, if present, tends to move in the direction of decreasing hydraulic potential, $\phi$ (Shreve, 1972). Assuming that the basal water pressure is equal to the overlying ice pressure, the hydraulic potential gradient (or water pressure gradient) is written as

$$
\nabla \phi=\rho_{\mathrm{i}} g \nabla z_{\mathrm{s}}+\left(\rho_{\mathrm{w}}-\rho_{\mathrm{i}}\right) g \nabla z_{\mathrm{b}},
$$

where $\rho_{\mathrm{w}}$ is the water density, $\rho_{\mathrm{i}}$ the ice density, $g$ the acceleration due to gravity and $z_{\mathrm{s}}$ and $z_{\mathrm{b}}$ the surface and bedrock elevation, respectively. Basal hydrology can furthermore be represented in terms of the subglacial water flux, which is a function of the basal melt rate. A continuity equation for basal water flow is given by

$$
\frac{\partial w}{\partial t}=-\nabla \cdot\left(\mathbf{v}_{\mathrm{w}} w\right)+\dot{m}_{\mathrm{b}},
$$

where $w$ is the thickness of the water layer $(m), \mathbf{v}_{w}$ the vertically integrated velocity of water in the layer $\left(\mathrm{m} \mathrm{a}^{-1}\right)$ and $\dot{m}_{\mathrm{b}}$ the basal melting rate $\left(\mathrm{m} \mathrm{a}^{-1}\right)$. If we consider steadystate conditions, the basal melting rate must balance the water flux divergence, or $\dot{m}_{\mathrm{b}}=\nabla \cdot\left(\mathbf{v}_{\mathrm{w}} w\right)$. The steady-state basal water flux, $\psi_{\mathrm{w}}=\left(\mathbf{v}_{\mathrm{w}} w\right)$, is obtained by integrating the basal melt rate, $\dot{m}_{\mathrm{b}}$, over the whole glacier area, starting at the hydraulic head in the direction of the hydraulic potential gradient, $\nabla \phi$. This can easily be done with a computer algorithm for calculating balance fluxes (Le Brocq and others, 2006).

Considering a uniform basal melting rate under McCall Glacier, the above algorithm allows for the determination of the direction of the subglacial water flow as well as its flux. Both are shown in Figure 3c, which shows how the subglacial drainage converges onto the talweg. Subglacial flow coming from the UC and MC follows the talweg of the hanging valley and stays close to the northern side of the valley, thus joining the LC subglacial hydraulic system downstream from the confluence area between UC/MC and LC. This creates a subglacial 'dry island' in the confluence area, as clearly depicted in Figure 3c. However, one has to keep in mind 

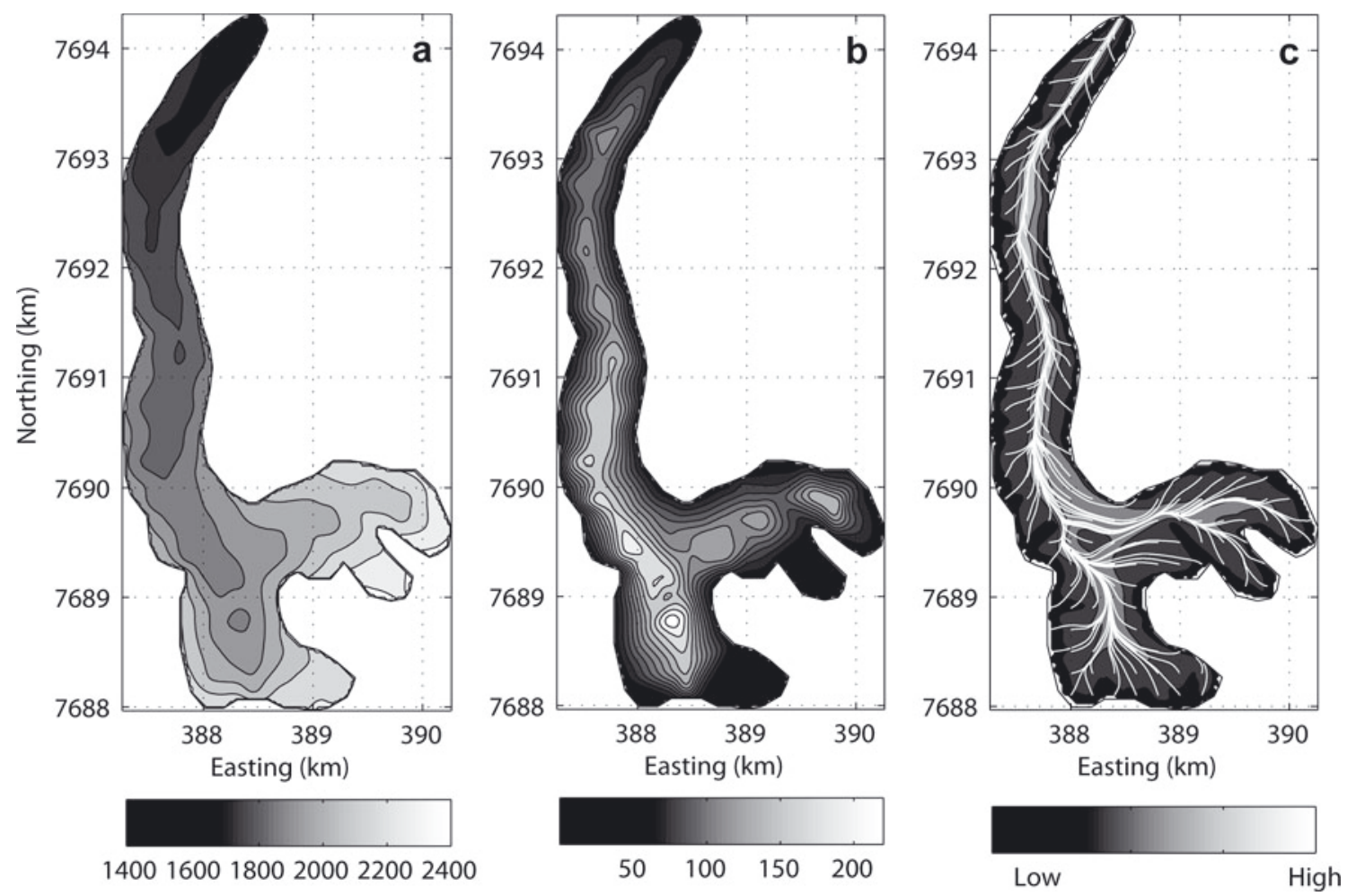

Fig. 3. (a) Bedrock topography (m a.s.l.) obtained after interpolation of the measured profiles; (b) ice thickness (m); (c) subglacial water flux and drainage based on the hydraulic potential gradient.

that the map represents the potential subglacial flow pattern, assuming that subglacial meltwater is produced along the whole glacier/bed contact. Results from the BRP analysis (below) show that this assumption is not likely to be valid, and that the drainage only applies to the lowermost section of the drainage basin (glacier tongue).

\section{BED REFLECTION POWER (BRP)}

To gain insight into the basal conditions (whether the glacier is frozen to the bed or not), it is convenient to calculate the reflected power from the radar signals. We consider the reflected signal to be consistent with a monochromatic sinusoidal wavetrain (Gades and others, 2000). As such, we can define the reflected power, $P$, within a time window, $t_{1}-t_{2}$, as proportional to

$$
P \equiv \frac{1}{2\left(t_{2}-t_{1}+1\right)} \sum_{i=t_{1}}^{t_{2}} A_{i}^{2},
$$

where $A_{i}$ is the recorded amplitude of the wave. Using Equation (3), we can calculate the reflection power of both the bed reflection wave (BRP) and the internal reflection waves (IRP), which are located between the end of the direct airwave and the beginning of the bed reflection wave (Gades and others, 2000). The BRP contains information on the structure and composition of the glacier bed. The IRP is a measure of the scatter and attenuation within the glacier ice. A variable time window is used for the calculation of the IRP, which is more suitable for shallow glaciers (Copland and Sharp, 2001), and which extends from $0.6 \mu$ s after the beginning of the airwave to $0.1 \mu$ s before the bed reflection wave. The BRP starts at the latter point and ends $0.4 \mu \mathrm{s}$ after the bed reflection wave.
If we assume that losses due to polarization and scattering at the ice/bed interface are minimal or constant, and that antenna characteristics and surface coupling are constant for all measurements, the only controls on the BRP are the loss due to two-way propagation through the ice (hence a function of ice thickness) and the strength of the basal reflection (Copland and Sharp, 2001).

The calculated IRP values are very low for McCall Glacier (Fig. 4a), and more than an order of magnitude lower than the BRP (an average of $39 \mathrm{mV}^{2} \mathrm{~ns}^{-1}$ for IRP compared to $802 \mathrm{mV}^{2} \mathrm{~ns}^{-1}$ for BRP), which increases confidence in the use of BRP as a proxy for basal variability.

More confidence in the robustness of BRP values for analyzing bed characteristics stems from the measurement of the same longitudinal section (as presented in Pattyn and others, 2005) 2 years apart under contrasting meteorological conditions (rainfall and abundant surface water runoff in 2003 compared to clear-sky conditions and nearfreezing air temperatures without surface runoff in 2005). Although exact co-location of measurements was not possible, a remarkable resemblance between the two profiles exists, both in ice thickness (Fig. 5a) and in the BRP signal (Fig. 5b).

Since BRP is directly related to the two-way travel time of the signal, hence ice thickness, it is convenient to correct for this bias. Figure 6 displays the relation between ice thicknesses and BRP values for all measurements and for those along the central flowline originating from the LC. However, since the BRP analysis only makes sense in relation to subglacial drainage characteristics, it is convenient to account only for the bed reflections along the central flowline, which correlate very well with ice thickness $\left(R^{2}=0.81\right)$. From the obtained relation $\left(\mathrm{BRP}^{\star}=58947.43 \mathrm{e}^{-0.038 H}\right)$, the BRP 

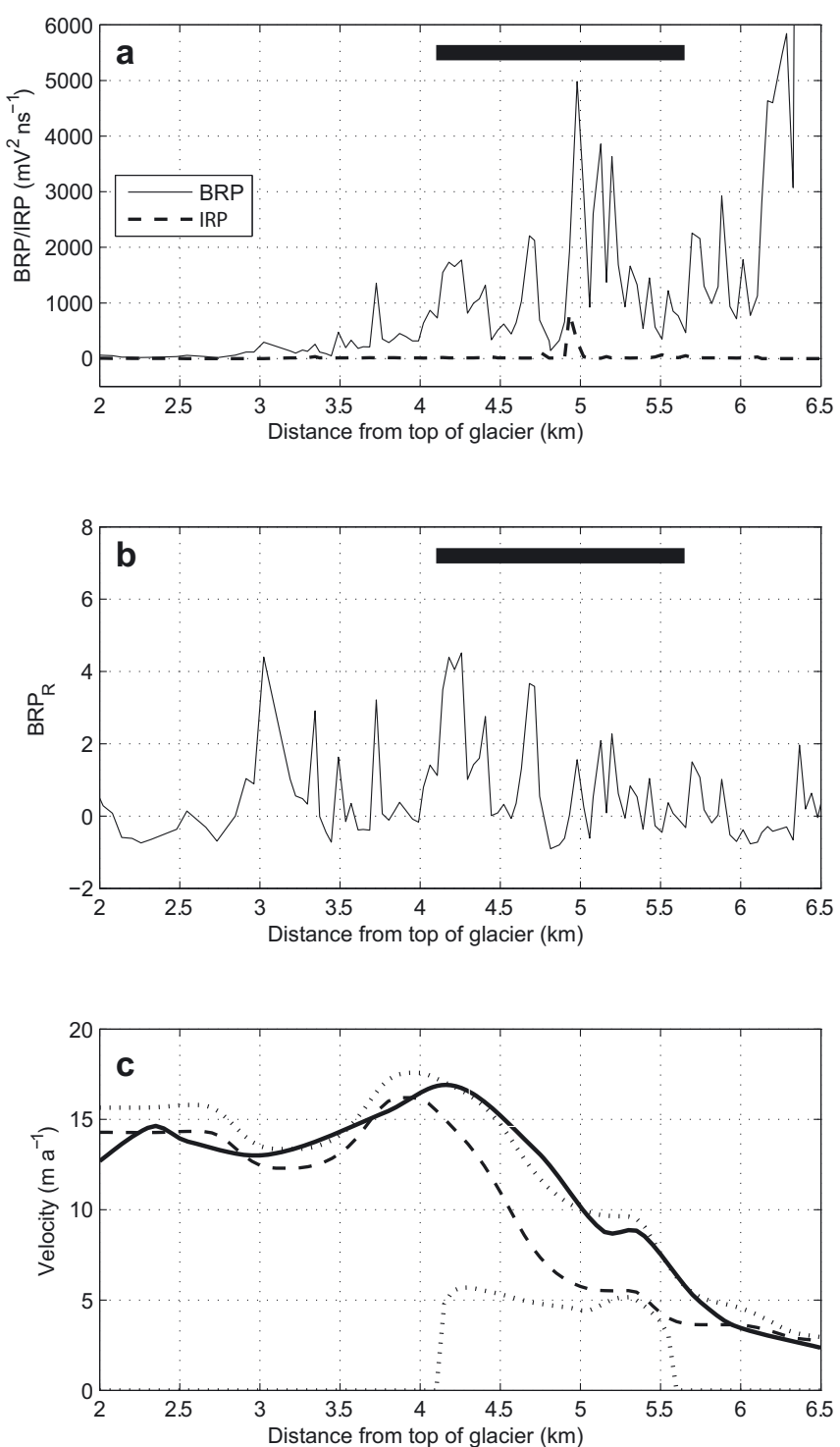

Fig. 4. (a) $B R P$ and IRP along the central flowline. (b) $B R P_{R}$ (corrected for ice thickness) along the central flowline. (c) Observed (solid curve) and predicted (dotted and dashed curves for with and without basal sliding, respectively) longitudinal velocities along the central flowline (adapted from Pattyn and others, 2005). The black bar delineates the area where basal sliding must occur (Rabus and Echelmeyer, 1997; Pattyn and others, 2005).

values can be normalized along the central flowline as

$$
\mathrm{BRP}_{\mathrm{R}}=\frac{\mathrm{BRP}}{\mathrm{BRP}^{\star}}-1 \text {. }
$$

In general, BRP values along the central profile are rather low at the upstream side and gradually increase downstream (Fig. 4a). At $\sim 3.7 \mathrm{~km}$, BRP values peak at $\sim 1500 \mathrm{mV}^{2} \mathrm{~ns}^{-1}$. Further downstream more peaks occur, and those between 4.0 and $4.5 \mathrm{~km}$ were attributed to the presence of water at the bottom, as it coincided with the onset of the sliding area (Fig. 4c; Rabus and Echelmeyer, 1997; Pattyn and others, 2005). However, even larger peaks appear downstream from this site. For instance, the major peak at $5.0 \mathrm{~km}$ coincides with the presence of multiple moulins. Here, larger values of IRP may point to anomalies in the ice, such as englacial water flow. It is therefore very likely that surface meltwater is collected through these conduits, reaches the bed and enhances its reflectivity. Similar mechanisms are observed
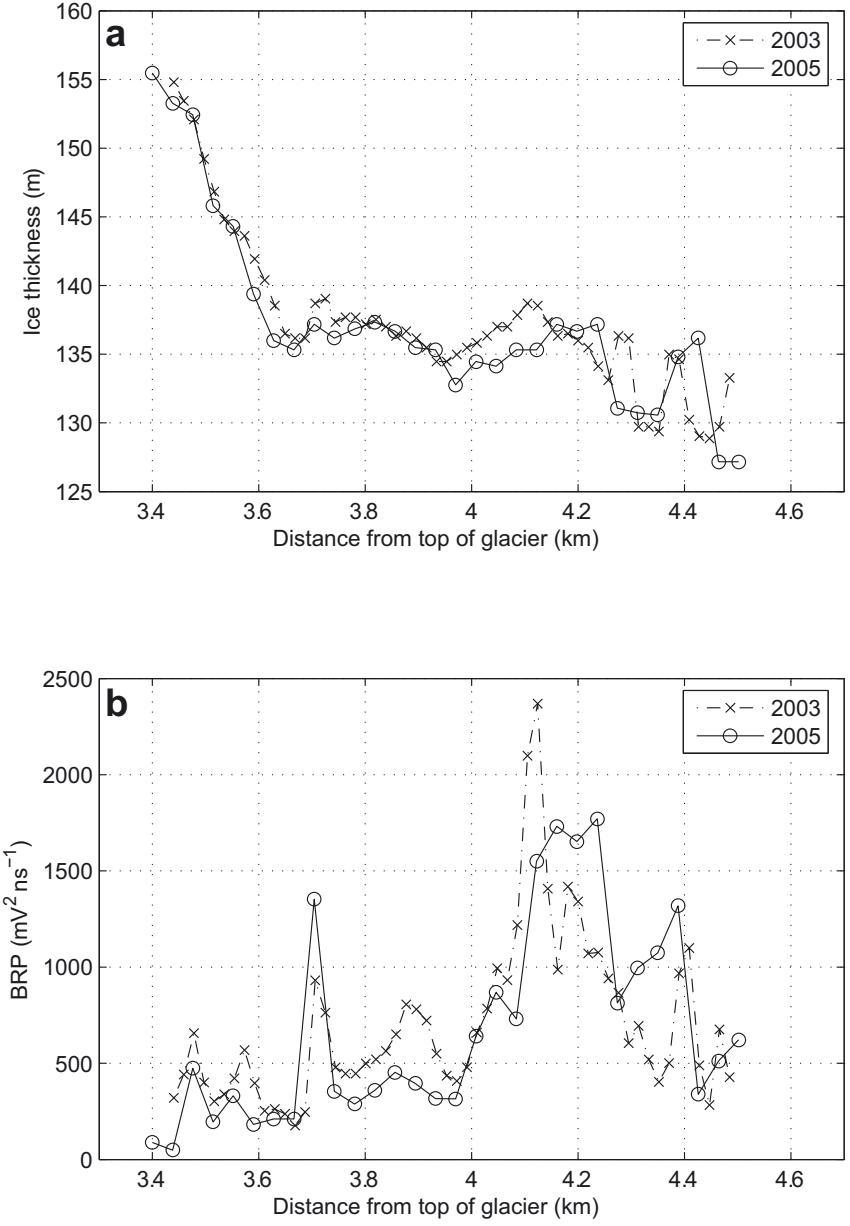

Fig. 5. Comparison of (a) ice thicknesses and (b) BRP values along the same section of longitudinal profile in the downstream area of McCall Glacier, measured in 2003 and 2005 under contrasting meteorological conditions. Values taken from figure $2 \mathrm{~b}$, Pattyn and others (2005).

elsewhere (Kohler, 1995). Subsequent peaks in BRP follow downstream, all coinciding with the presence of moulins. The high values of BRP at the terminus of McCall Glacier are probably related to the emergence of basal water flow.

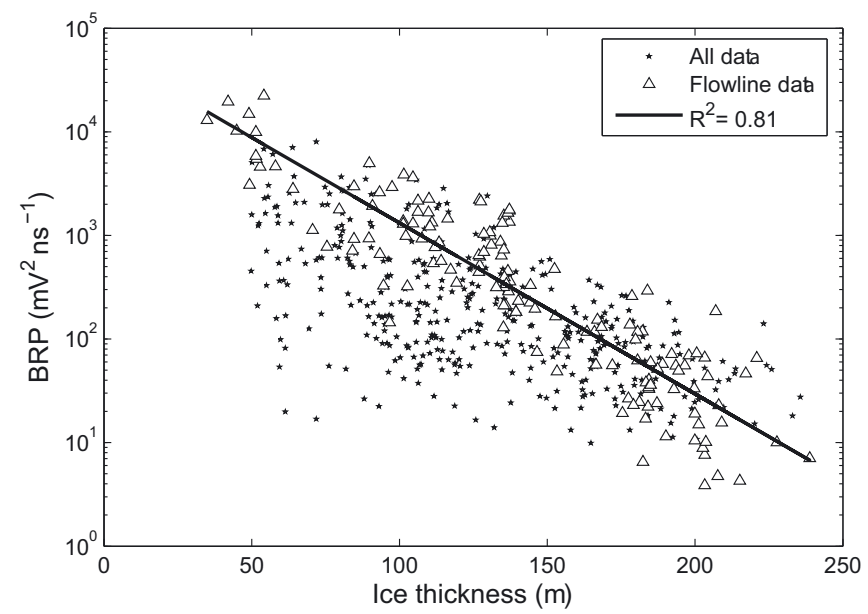

Fig. 6. Relation between ice thickness and BRP for all measurements on McCall Glacier (stars) and for the central flowline (triangles). The correlation is given for the central flowline data $\left(R^{2}=0.81\right)$. 
However, the terminus area is covered with large amounts of debris, which may hamper the interpretation of basal reflection values.

The normalized basal reflection $\left(B R P_{R}\right)$ is shown in Figure $4 \mathrm{~b}$, where positive values indicate a higher than expected bed reflection. Although it is difficult to link $B R P_{R}$ to the presence of water, high values of $B R P_{R}$ occur at least $1 \mathrm{~km}$ upstream from the presumed zone of basal sliding. This may point to the presence of subglacial meltwater that does not actively influence the glacier dynamics. Further upstream $B R P_{R}$ values remain very low. Near the front, $B R P_{R}$ tends to be lower and event negative, which may point to frozen bedrock. This coincides with the area where basal sliding ceases, as corroborated by numerical model experiments (Fig. 4c, adapted from Pattyn and others, 2005). This type of behavior is characteristic of a number of polythermal glaciers, and McCall Glacier in particular. Due to the thinner ice, basal ice temperatures are generally lower near the glacier terminus. The presence of the basal temperate layer is mainly due to strong vertical temperature advection gradients near the surface (Rabus and Echelmeyer, 2002).

\section{DISCUSSION AND CONCLUSIONS}

Based on several RES campaigns on McCall Glacier, the subglacial topography has been mapped, showing a large discrepancy between the main glacier trunk coming from the LC (lower cirque) and a hanging glacier coming from the $\mathrm{UC} / \mathrm{MC}$ (upper and middle cirques), the latter two forming the present accumulation area of McCall Glacier. From the calculated ice-thickness distribution, the total ice volume of McCall Glacier is estimated at $\sim 0.5 \mathrm{~km}^{3}$.

For the central flowline, the BRP was calculated from the raw radar signals and corrected for ice thickness. From $\sim 4 \mathrm{~km}$ downstream from the head of the flowline through LC, BRP peaks for the next $1.5-2 \mathrm{~km}$. This zone corresponds to the area that was previously determined as a zone where basal sliding is prevalent (Rabus and Echelmeyer, 1997; Pattyn and others, 2005). The highest peak values of BRP correspond to the presence of moulins, which suggests flow of surface meltwater to the base of the glacier. The BRP shows no significant variability for the whole upstream part of the glacier, i.e. upstream from $4 \mathrm{~km}$. Such low values may point to ice frozen to the bedrock. However, model results indicate that large portions of the basal ice are at the pressure-melting point (Pattyn and others, 2005). Although many supraglacial water channels are observed in the upstream part, it lacks moulins. Therefore, it is likely that meltwater, transferred from the surface via moulins to the bed, is reflected in the BRP signal.

An analysis of the subglacial hydrological network beneath McCall Glacier shows the convergence of the subglacial network to the central flowline (talweg). The highest values of subglacial water flux coincide with high values of BRP, as is expected. The subglacial drainage system, shown as a complex pattern in the upstream part of the glacier and its confluence area, is probably not active, since BRP values are generally low in this area and moulins are not observed.
Nevertheless, with a rapidly changing glacier geometry, a change in the subglacial hydrological network may be expected in the future.

\section{ACKNOWLEDGEMENTS}

This research forms part of the US National Science Foundation's Freshwater Initiative (OPPARCSS) and is partly financed by a FWO-Vlaanderen 'Krediet aan navorsers' project. C. Delcourt is supported by a Fonds pour la Formation à la Recherche dans I'Industrie et dans I'Agriculture (Belgium) (FRIA) grant of the FRS-FNRS (Fonds National de la Recherche Scientifique). The authors are indebted to all members of the 2003, 2005 and 2006 McCall field parties, and to K. Irving, B. Rabus and K. Nolan in particular. We thank R. Jacobel and A. Fountain for constructive remarks, and $\mathrm{H}$. Conway for editing the paper.

\section{REFERENCES}

Copland, L. and M. Sharp. 2001. Mapping thermal and hydrological conditions beneath a polythermal glacier with radio-echo sounding. J. Glaciol., 47(157), 232-242.

Delcourt, C., F. Pattyn and M. Nolan. 2008. Modelling historical and recent mass loss of McCall Glacier, Alaska, USA. Cryosphere, 2(1), 23-31.

Gades, A.M., C.F. Raymond, H. Conway and R.W. Jacobel. 2000. Bed properties of Siple Dome and adjacent ice streams, West Antarctica, Inferred from radio-echo sounding measurements. J. Glaciol, 46(152), 88-94.

Kohler, J. 1995. Determining the extent of pressurized flow beneath Storglaciären, Sweden, using results of tracer experiments and measurements of input and output discharge. J. Glaciol., 41(138), 217-231.

Le Brocq, A., A.J. Payne and M.J. Siegert. 2006. West-Antarctic balance calculations: impact of flux-routing algorithm, smoothing algorithm and topography. Comput. Geosci., 32, 1780-1795.

Narod, B.B. and G.K.C. Clarke. 1994. Miniature high-power impulse transmitter for radio-echo sounding. J. Glaciol., 40(134), 190-194.

Nolan, M., A.A. Arendt, B.T. Rabus and L. Hinzman. 2005. Volume change of McCall Glacier, Arctic Alaska, from 1956 to 2003. Ann. Glaciol., 42, 409-416.

Pattyn, F. and 6 others. 2003. Ice dynamics and basal properties of Sofiyskiy glacier, Altai mountains, Russia, based on DGPS and radio-echo sounding surveys. Ann. Glaciol., 37, 286-292.

Pattyn, F., M. Nolan, B.T. Rabus and S. Takahashi. 2005. Localized basal motion of a polythermal Arctic glacier: McCall Glacier, Alaska, USA. Ann. Glaciol., 40, 47-51.

Rabus, B.T. and K.A. Echelmeyer. 1997. The flow of a polythermal glacier: McCall Glacier, Alaska, U.S.A. J. Glaciol., 43(145), 522-536.

Rabus, B.T. and K.A. Echelmeyer. 2002. Increase of $10 \mathrm{~m}$ ice temperature: climate warming or glacier thinning? J. Glaciol., 48(161), 279-286.

Rabus, B.T., K.A. Echelmeyer, D. Trabant and C. Benson. 1995. Recent changes of McCall Glacier, Alaska. Ann. Glaciol., 21, 231-239.

Shreve, R.L. 1972. Movement of water in glaciers. J. Glaciol., 11(62), 205-214. 